DOI 10. 18307/2017. 0204

(C) 2017 by Journal of Lake Sciences

\title{
巢湖流域塘西河上游分流制系统降雨径流污染特征及初期冲刷 效应"
}

\author{
周 峰 ${ }^{1}$, 曹明明 ${ }^{1}$, 柯 凡 ${ }^{2,3 * *}$, 张 汶 $^{4}$, 冯慕华 ${ }^{2}$, 李文朝 ${ }^{2,3}$ \\ (1:西北大学城市与环境学院,西安 710127) \\ (2: 中国科学院南京地理与湖泊研究所,南京 210008) \\ (3: 江苏高校水处理技术与材料协同创新中心,苏州 215009) \\ (4:安徽省环境科学研究院,合肥 230001)
}

\begin{abstract}
摘 要: 研究城市径流水质变化及初期冲刷效应对控制与治理城市径流污染具有重要指导意义. 对塘西河上游 6 次降雨 径流水质水量进行监测分析, 计算次降雨径流平均浓度 $(E M C)$ 和单位面积次降雨径流污染负荷 $(E P L)$, 作 $\mathrm{M}(\mathrm{V})$ 曲线图 研究初期冲刷现象. 结果表明: 降雨径流中悬浮物 ( $\mathrm{SS}$ )、化学需氧量 $\left(\mathrm{COD}_{\mathrm{Cr}}\right)$ 和总磷 ( TP) 的 $E M C$ 值相对较大; $\mathrm{SS}$ 的 $E M C$ 值波动最为显著; 总氮 $(\mathrm{TN}) 、 \mathrm{TP} 、 \mathrm{COD}_{\mathrm{Cr}} \mathrm{SS}$ 间的 $E M C$ 值均呈正相关; $\mathrm{TN}$ 的 $E M C$ 值与降雨量呈负相关性. 各污染物 $E P L$ 值与各降雨特征间均呈正相关性,经估算 2015 年研究区在 6-8 月共有 $10.38 \mathrm{t}$ TN、2.29 t TP、1022.43 t SS、161.70 t COD $\mathrm{Cr}$ 和 $5.18 \mathrm{t} \mathrm{NH}-\mathrm{N}$ 随降雨径流排人巢湖; 降雨量和雨前干期是城市径流污染的主要影响因素; 以 $F F 50>50$ 为初期冲刷效应 判别依据, 5 种污染物均有初期冲刷效应出现, 冲刷程度表现为 $\mathrm{SS}>\mathrm{COD} \mathrm{Cr}_{\mathrm{Cr}}>\mathrm{TP}>\mathrm{TN}>\mathrm{NH}_{3}-\mathrm{N}$; 各水质指标的初期冲刷强度 与降雨特征之间无相关性; 雨型对初期冲刷现象影响较大; 当降雨强度达 $1.36 \mathrm{~mm} / \mathrm{h}$ 即有径流汇集流出时开始截流,截流 时间取 $440 \mathrm{~min}$,截取的最大径流量取 $224319.14 \mathrm{~m}^{3}$.
\end{abstract}

关键词: 塘西河;分流制排水系统; 城市雨水径流;初期冲刷; $M(V)$ 曲线;巢湖流域

\section{Analysis of pollution characteristics and first flush effect in rainfall runoff in separate storm sewer system in upstream of Tangxi River, Chaohu Catchment}

\author{
ZHOU Feng $^{1}$, CAO Mingming ${ }^{1}$, KE Fan $^{2,3 * *}$, ZHANG Liu ${ }^{4}$, FENG Muhua $^{2} \&$ LI Wenchao ${ }^{2,3}$ \\ (1: College of Urban and Environmental Sciences, Northwestern University, Xi'an 710127, P.R.China) \\ (2: Nanjing Institute of Geography and Limnology, Chinese Academy of Sciences, Nanjing 210008, P.R.China) \\ (3: Jiangsu College of Water Treatment Technology and Material Collaborative Innovation Center, Chinese Academy of Sci- \\ ences, Suzhou 215009, P.R.China) \\ (4: Anhui Institute of Environmental Science, Hefei 230001, P.R.China)
}

Abstract: Understanding the runoff water quality and first flush effects can guide the management of urban runoff pollution. Six rainfall events were monitored and event mean concentration $(E M C)$ and event pollutant loads per unit area $(E P L)$ were calculated in the upstreams of Tangxi River. The $\mathrm{M}(\mathrm{V})$ curve was used to show the first flush effects. The results showed that the $E M C$ of suspended solids( $\mathrm{SS})$, chemical oxygen demand $\left(\mathrm{COD}_{\mathrm{Cr}}\right)$ and total phosphorous ( TP ) were relatively large in rainfall runoff. The $E M C$ of $\mathrm{SS}$ has the most significant fluctuations. There was a positive correlation beween total nitrogen( TN), TP, COD $\mathrm{Cr}$ and $\mathrm{SS}$. The $E M C$ of TN was negatively correlated with the rainfall. The $E P L$ of runoff water pollution has a positive correlation with the rainfall characteristics. Approximately 10.38 t TN, 2.29 t TP, 1022.43 t SS, 161.70 t $\mathrm{COD}_{\mathrm{Cr}}$ and $5.18 \mathrm{t} \mathrm{NH}$ - $\mathrm{N}$ were input into the Lake Chaohu via runoffs in June, July, and August, 2015. Rainfall and antecedent dry weather period were the main influencing factors of the urban storm runoff pollution. Five kinds of pollutants had their own first flush effects, employing the $F F 50>50$ as

* 国家水体污染控制与治理科技重大专项 (2012ZX07103) 资助. 2016-01-08 收稿; 2016-06-28 收修改稿. 周峰 (1990 ), 男, 硕士研究生;E-mail:550296221@ qq.com.

** 通信作者;E-mail: fke@ niglas.ac.cn. 
the standard, the magnitude of the first flush effect was $\mathrm{SS}>\mathrm{COD}_{\mathrm{Cr}}>\mathrm{TP}>\mathrm{TN}>\mathrm{NH}_{3}-\mathrm{N}$. There was no correlation between the magnitude of first flush and rainfalls. The rainfall pattern could have a strong effect on the first flush effect. It is recommended to closure the runoffs when the rain intensity reaches to $1.36 \mathrm{~mm} / \mathrm{h}$, i.e. the runoffs begin to converge with the duration of $440 \mathrm{~min}$, and the maximum intercept runoff amounts is $224319.14 \mathrm{~m}^{3}$.

Keywords: Tangxi River; separate storm sewer system; urban stormwater runoff; first flush; M(V) curve; Chaohu Catchment

在湖泊污染治理过程中, 随着点源污染控制程度的提高, 面源污染越来越成为湖泊水质净化的重点 ${ }^{[1-2]}$. 随着城市化的发展, 不透水下垫面面积的增加, 降雨时因雨水冲刷而形成的径流污染日益严重, 大中型城市 在暴雨事件中的径流污染和排洪防涝是建设海绵城市过程中遇到的问题与挑战 ${ }^{[3]}$. 城市雨水径流中含有烷 烃物 ${ }^{[4]} 、$ 大肠杆菌 ${ }^{[5]}$ 、重金属 ${ }^{[6-7]}$ 、氮磷营养盐 ${ }^{[8-9]}$ 和悬浮物 ${ }^{[10]}$ 等多类污染物, 如果不经处理直接排放, 会对 湖泊等受纳水体的水质产生严重影响 ${ }^{[11]}$, 目前国内外针对雨水径流中污染物和重金属的研究比较多. 在城 市降雨径流形成的初期阶段, 径流中携带大量污染物的情况称为初期冲刷效应 ${ }^{[2-13]}$, 这一部分雨水径流被 定义为初期雨水 ${ }^{[14]}$. 如果在降雨过程中表现出了较为强烈的初期冲刷现象, 可以将携带大部分污染物的初 期雨水进行截流处理, 净化后再排放. 所以初期冲刷效应的研究对控制治理城市降雨径流污染有重要指导 意义.

初期冲刷形成过程复杂, 影响因素繁多, 雨前干期、降雨类型、下垫面土地利用类型和汇水面积等均会 对初期冲刷效应产生显著影响 ${ }^{[15]}$. 目前研究中, 常用的初期冲刷效应判定方法有 $\mathrm{M}(\mathrm{V})$ 曲线法 ${ }^{[16]}$ 和 b 参数 法 ${ }^{[17]}$, 其中 $\mathrm{M}(\mathrm{V})$ 曲线法应用最为广泛. $\mathrm{M}(\mathrm{V})$ 曲线法是基于污染物质量累计比例和径流量累计比例所作 的曲线,对角线表示污染物随径流均匀排放, $F F n$ 表示前 $n$ \% 雨水径流中所携带污染物的百分比. Saget 等使 用 FF30>80 作为标准来判定初期冲刷现象的发生 ${ }^{[18]}$,但此标准过于严格, Sun 等对法国一城市 2004-2011 年间 162 场降雨进行 $\mathrm{M}(\mathrm{V})$ 曲线分析 ${ }^{[10]}$, 发现所有降雨事件中均未出现 FF30>80 的现象. Gupta 等认为当 曲线位于判别线上方, 即 $F F 50>50$ 时便可说明出现初期冲刷现象 ${ }^{[19]}$, 曲线距判别线距离越大, 冲刷越明显.

根据研究区特征的不同, 对初期冲刷的研究可分为小汇水面源头冲刷和管渠冲刷 ${ }^{[14]}$. 小汇水面源头冲 刷是指居民区 ${ }^{[20]}$ 、高速公路 ${ }^{[21]}$ 、停车场 ${ }^{[22]}$ 等土地利用类型单一、汇水面积较小的冲刷过程; 管渠冲刷是径 流对多个小汇水面和排水管渠的综合冲刷过程, 汇水面积较大, 土地利用类型复杂. 管渠冲刷包括合流制溢 流冲刷 ${ }^{[23]}$ 和雨水管网冲刷 ${ }^{[24-25]}$, 合流制溢流冲刷因管内沉积物和截流设施等因素的影响, 冲刷作用更为复 杂 ${ }^{[26]}$, 目前对管渠冲刷的研究对象多是合流制管道, 但随着城市化的发展, 越来越多的新区在规划建设时实 行雨污分流, 老城区的合流制系统也在逐渐进行分流制改造或替换, 所以针对雨水管网冲刷的研究对于控 制城市面源污染更具有指导意义.

巢湖是长江水系下游浅水型湖泊, 位于安徽省中部, 是我国五大淡水湖之一, 由于水质较差, 属于我国 水污染防治重点对象之一. 本研究选取巢湖流域塘西河上游汇水区为研究对象, 该区域汇水面积相对较大, 土地利用类型多样且排水系统为分流制排水系统, 降雨时产生的初期冲刷为典型的雨水管网冲刷, 所以研 究该区域的初期冲刷现象具有一定代表性. 塘西河整治工程已基本完成, 所以由降雨冲刷形成的初期雨水 是塘西河的主要污染源, 初期雨水经雨水管网汇人塘西河, 然后流人巢湖. 为了防止塘西河在降雨天气下携 带大量污染物流人巢湖, 需要对初期雨水的水质水量、污染特征及冲刷特性进行研究, 以期为城市面源污染 的防治提供参考.

\section{1 材料与方法}

\section{1 研究区概况}

合肥位于安徽省中部, 长江、淮河之间, 巢湖之滨, 年平均降雨量为 $996.41 \mathrm{~mm}$, 降雨集中在每年的 $6 、 7 、 8$ 月份, 3 个月总降雨量平均占全年的 $43.55 \%$ ( 图 1) (数据来源于中央气象网).

塘西河是流人巢湖的重要水系之一, 是一条季节性、雨源性河流, 全长 $12.7 \mathrm{~km}$, 流域面积 $50 \mathrm{~km}^{2[27]}$, 上 游位于经济开发区, 经济开发区排水管道系统为雨污分流制, 但为了缓解当地污水处理厂的压力, 每天会有 少量生活污水排人到雨水管道中, 所以雨污分流得不彻底, 经监测估算每天会有 $100 \mathrm{~m}^{3}$ 左右的污水排人雨 水管道中, 因污水水量太小, 在降雨产生径流的过程中其影响可以忽略. 塘西河上游汇水面积约 $24.83 \mathrm{~km}^{2}$, 
雨水经两路箱涵流人塘西河,一路通过 $4.0 \mathrm{~m} \times 2.5 \mathrm{~m}$ 的箱涵和南艳湖相连, 另一路通过两根 $4.0 \mathrm{~m} \times 2.5 \mathrm{~m}$ 的箱涵与经济开发区雨水管网连接. 由于南艳湖的自 净与调节作用, 降雨时产生的径流水质较好, 流量变 化慢, 可直接排人塘西河. 经经济开发区雨水管网从 另一路箱涵排出的雨水径流是本次研究的重点.

研究区 (图 2) 土地利用类型相对较复杂, 以生活 区、工业区和透水区为主.工业区占总面积的 $26.41 \%$, 雨水径流系数为 0.9 ; 透水区占 $26.46 \%$, 透水区包括 草地、林地、裸地等雨水可以快速渗人土壤的地区, 雨 水径流系数为 0.15 ; 生活区占 $31.20 \%$,包括居民小 区、广场、商场等地区,雨水径流系数为 0.9 ; 道路面积 占 $15.92 \%$, 雨水径流系数为 0.9 . 研究区综合径流系数 为 0.7 , 不透水地区占汇水面积的 $73.54 \%$, 平均坡度为

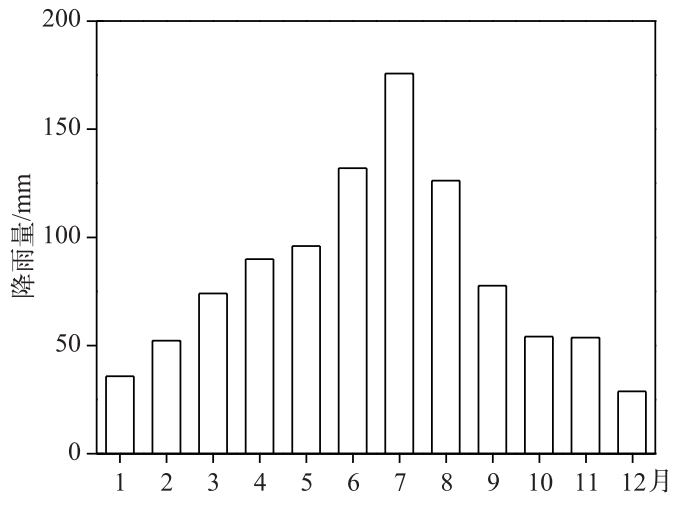

图 1 合肥市月平均降雨量

Fig. 1 Monthly average rainfall in Hefei City $0.47 \%$,排水管道主渠道长 $13.69 \mathrm{~km}$.

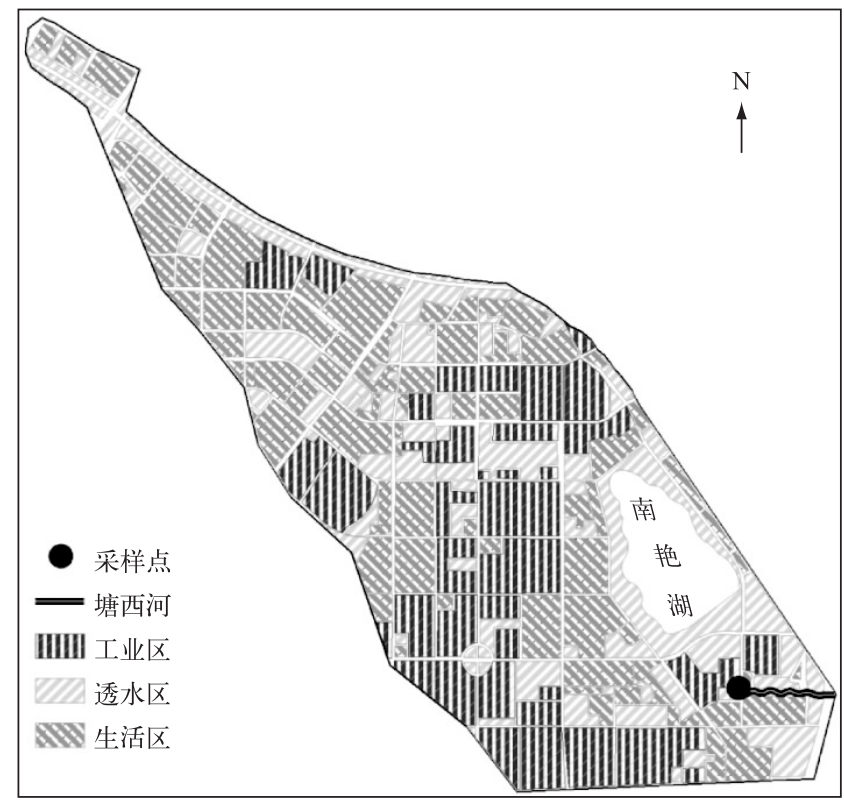

图 2 研究区概况

Fig.2 Map of study areas

\section{2 样品采集与分析}

采样点位于与雨水管网连接的箱涵出口处,采集的径流存储于 $1 \mathrm{~L}$ 洁净聚乙烯瓶内. 样品采集使用“前 密后疏”方式: 从有径流从采样点流出时开始计时. 第 $1 \mathrm{~h}$ 每 $5 \mathrm{~min}$ 采水样 1 瓶; 第 $2 \mathrm{~h}$ 每 $10 \mathrm{~min}$ 采 1 次; 第 $3 \mathrm{~h}$ 每 $20 \mathrm{~min}$ 采 1 次;第 $4 \mathrm{~h}$ 每 $30 \mathrm{~min}$ 采 1 次; $4 \mathrm{~h}$ 后每小时采 1 次. 采样同时测定水位以计算流量, 使用自 动式雨量计记录降雨数据. 采样期间的降雨特征见表 1. 采样结束后立即将水样送到实验室进行预处理. 对 雨水径流的测试指标包括总氮 $(\mathrm{TN})$ 、总磷 $(\mathrm{TP})$ 、悬浮物 $(\mathrm{SS})$ 、化学需氧量 $\left(\mathrm{COD}_{\mathrm{Cr}}\right)$ 和氨氮 $\left(\mathrm{NH}_{3}-\mathrm{N}\right)$, 指标的 测定参照文献 $[28]$. 
表 1 降雨特征

Tab.1 Rainfall characteristics

\begin{tabular}{cccccccc}
\hline 日期 & $\begin{array}{c}\text { 降雨量/ } \\
\mathrm{mm}\end{array}$ & $\begin{array}{c}\text { 降雨历时/ } \\
\mathrm{min}\end{array}$ & $\begin{array}{c}\text { 采样历时/ } \\
\min \end{array}$ & $\begin{array}{c}\text { 平均雨强/ } \\
(\mathrm{mm} / \mathrm{h})\end{array}$ & $\begin{array}{c}\text { 最大雨强/ } \\
(\mathrm{mm} / \mathrm{h})\end{array}$ & $\begin{array}{c}\text { 雨前干期/ } \\
\mathrm{d}\end{array}$ & $\begin{array}{c}\text { 产生径流/ } \\
\mathrm{m}^{3}\end{array}$ \\
\hline $2015-6-16$ & 78.5 & 480 & 907 & 9.81 & 60.2 & 13 & 628344.93 \\
$2015-6-26$ & 4.5 & 185 & 357 & 1.45 & 15.0 & 1 & 13400.09 \\
$2015-7-16$ & 5.5 & 130 & 395 & 2.53 & 12.8 & 4 & 16357.19 \\
$2015-7-23$ & 6.0 & 80 & 319 & 4.50 & 13.4 & 7 & 19436.69 \\
$2015-8-9$ & 21.0 & 270 & 440 & 4.66 & 26.6 & 3 & 86008.07 \\
$2015-8-19$ & 2.5 & 110 & 300 & 1.36 & 5.2 & 3 & 6674.00 \\
\hline
\end{tabular}

\section{3 研究方法}

每场降雨产生的径流中各指标的平均浓度以次降雨径流平均浓度 $(E M C)^{[29]}$ 表示, 其实质是雨水径流 中瞬时污染物浓度的流量加权平均数, 其计算公式为:

$$
E M C=\frac{M}{V}=\frac{\int_{0}^{t} C_{t} \cdot Q_{t} \cdot \mathrm{d} t}{\int_{0}^{t} Q_{t} \cdot \mathrm{d} t}
$$

在每场降雨过程中,研究区单位面积上产生污染物的量以单位面积次降雨径流污染负荷 $(E P L)^{[30]}$ 表 示,其计算公式为:

$$
E P L=\frac{M}{A}=\frac{\int_{0}^{t} C_{t} \cdot Q_{t} \cdot \mathrm{d} t}{A}
$$

式中, $M$ 为污染物总量 $(\mathrm{g}), V$ 为总径流量 $\left(\mathrm{m}^{3}\right), C_{t}$ 为 $t$ 时刻污染物浓度 $(\mathrm{mg} / \mathrm{L}), Q_{t}$ 为 $t$ 时刻径流量 $\left(\mathrm{m}^{3} / \mathrm{s}\right)$, $A$ 为研究区面积 $\left(\mathrm{km}^{2}\right)$.

通过作 $\mathrm{M}(\mathrm{V})$ 曲线图来研究降雨过程中的初期冲刷现象, 以 FF50>50 为判定初期冲刷现象出现的 标准.

\section{2 结果与讨论}

\section{1 雨水径流水质特征}

6 次降雨形成的径流中污染物浓度变化趋势基本一致,均表现为在径流形成初期达到峰值,然后降低, 其 中 6 月 16 日此趋势表现得最为明显. 6 月 16 日各污染物浓度峰值出现在径流形成初期, 且波动较大, 然后迅 速下降,变化趋于平稳 (图 3). 与小汇水面源头冲刷相比较,除前期浓度变化波动较大外,趋势基本相同.

由于研究对象属于大汇水面积的管渠冲刷, 雨水管道人口多, 降雨形成的径流经雨水管网汇集后在采 样点排出. 汇水区可分为多个大小不一的小汇水面,各个小汇水面距采样点的远近不同, 因此各个小汇水面 所汇集的雨水径流经管渠到达采样点的时间长短及污染物浓度存在一定差异, 不同浓度径流混合过程的复 杂性和随机性导致各污染物浓度波动变化较大.

6 场降雨径流中污染物 $E M C$ 值可以看出, 同一种污染物 $E M C$ 值在不同降雨过程中波动较大, 其中 $\mathrm{SS}$ 的 $E M C$ 值波动最为显著 (表 2). 目前合肥地表水体水质控制目标为准 IV 类标准, 将 6 场降雨产生的地表径 流中污染物 $E M C$ 值与准 $\mathrm{I}$ 类标准和地表水 $\mathrm{V}$ 类水标准进行对比, 污染物 $E M C$ 的平均值均超出地表水 $\mathrm{V}$ 类 水标准, 说明污染较为严重, 其中 $\mathrm{TN}$ 和 $\mathrm{COD}_{\mathrm{Cr}}$ 的 $E M C$ 值分别超过地表水 $\mathrm{V}$ 类标准的 2.44 倍和 2.15 倍; 与准 $\mathrm{IV}$ 类标准比较, $\mathrm{TN}$ 和 $\mathrm{NH}_{3}-\mathrm{N}$ 的 $E M C$ 平均值均未超标, 但准 $\mathrm{IV}$ 类标准对 $\mathrm{TP}$ 和 $\mathrm{COD}_{\mathrm{Cr}}$ 要求更为严格, $\mathrm{TP}$ 和 $\mathrm{COD}_{\mathrm{Cr}}$ 的 $E M C$ 平均值分别超出准 $\mathrm{IV}$ 类标准 1.97 倍和 2.86 倍. 谢继锋等 ${ }^{\left[{ }^{[1]}\right.}$ 在合肥对不同下垫面的雨水径流 和自然雨水的水质特征进行研究, 表明自然雨水中 TN 浓度平均值为 $4.631 \pm 3.614 \mathrm{mg} / \mathrm{L}$, 与本次研究中 TN 的 $E M C$ 值相近, 说明研究区雨水径流中 $\mathrm{TN}$ 主要来自于降雨过程中的淋溶作用. 谢继锋等 ${ }^{[31]}$ 研究的下垫面 

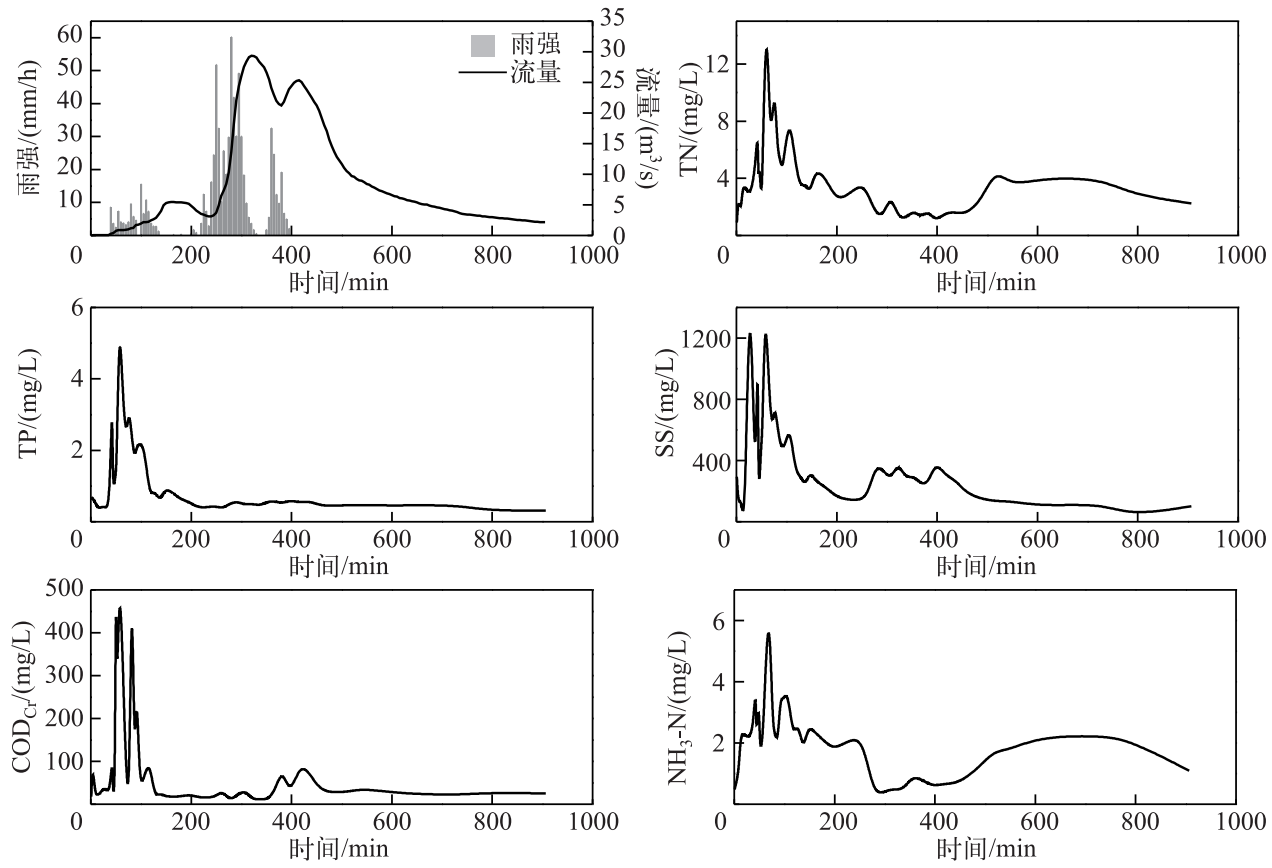

图 36 月 16 日径流中各污染物浓度变化

Fig.3 Change of pollutants concentration in runoff on June 16th

包括草地、屋面、校园内路面和校园外路面 4 种类型, 与其数据相比, 本次研究中 $\mathrm{TN} 、 \mathrm{TP} 、 \mathrm{COD}_{\mathrm{Cr}}$ 和 $\mathrm{SS}$ 的 $E M C$ 值均高于草地、屋面和校内道路径流中的平均浓度, 均低于校外道路径流中的平均浓度, 说明研究区径流中 各污染物的 $E M C$ 值是雨水对不同下垫面冲刷的综合作用结果.

以目前合肥市施行的准 $I V$ 类标准为参照, 如果建设调蓄净化池对研究区初期雨水进行处理, $\mathrm{COD}_{\mathrm{Cr}}$ 和 $\mathrm{TP}$ 是主要处理对象, 考虑到磷是水体富营养化的主要影响因素之一, 初期雨水中的磷要采取措施进行深度 处理. 6 场降雨过程中 $\mathrm{SS}$ 的 $E M C$ 值变化范围是 $46.82 \sim 377.86 \mathrm{mg} / \mathrm{L}$, 平均值为 $161.05 \mathrm{mg} / \mathrm{L}$, 浓度变化波动 大且污染显著, 因此对初期雨水的 $\mathrm{SS}$ 处理也要重点考虑. $\mathrm{TN}$ 和 $\mathrm{NH}_{3}-\mathrm{N}$ 的 $E M C$ 平均值虽未超标, 但两者在 径流形成初期时存在较高的瞬时浓度, TN 浓度最高可达 $14.05 \mathrm{mg} / \mathrm{L}, \mathrm{NH}_{3}-\mathrm{N}$ 最高浓度达 $7.80 \mathrm{mg} / \mathrm{L}$, 因此初 期雨水中氮的影响不可忽视.

表 2 污染物 $E M C$ 值

Tab.2 EMC of pollutants

\begin{tabular}{cccccc}
\hline \multirow{2}{*}{ 日期 } & \multicolumn{5}{c}{$E M C /(\mathrm{mg} / \mathrm{L})$} \\
\cline { 2 - 5 } & $\mathrm{TN}$ & $\mathrm{TP}$ & $\mathrm{COD}_{\mathrm{Cr}}$ & $\mathrm{SS}$ & $\mathrm{NH}_{3}-\mathrm{N}$ \\
\hline $2015-6-16$ & 2.36 & 0.52 & 34.11 & 234.24 & 1.17 \\
$2015-6-26$ & 5.52 & 0.83 & 111.82 & 377.86 & 2.29 \\
$2015-7-16$ & 5.04 & 0.49 & 26.37 & 46.82 & 2.00 \\
$2015-7-23$ & 5.39 & 0.69 & 176.81 & 80.11 & 3.40 \\
$2015-8-9$ & 3.68 & 0.48 & 68.51 & 162.97 & 1.01 \\
$2015-8-19$ & 7.23 & 0.55 & 97.30 & 64.33 & 2.02 \\
\hline 平均值 & $4.87 \pm 1.53$ & $0.59 \pm 0.13$ & $85.82 \pm 50.98$ & $161.05 \pm 161.42$ & $2.15 \pm 0.88$ \\
V 类水 & 2.00 & 0.40 & 40.00 & - & 2.00 \\
准 $\mathrm{I}$ 类 & 10.00 & 0.30 & 30.00 & - & 2.50 \\
\hline
\end{tabular}


6 场降雨过程中 $E P L$ 值可知, 不同降雨过程中 $E P L$ 值差异很大 (表 3). Qin 等 ${ }^{[30]}$ 对深圳某地区的降雨 径流污染特征进行了研究, 汇水面积与本次研究相近, 排水系统为合流制, 选取本次研究中降雨量相近的降 雨事件与其进行对比, 发现 $\mathrm{TN} 、 \mathrm{COD}_{\mathrm{Cr}} 、 \mathrm{SS}$ 和 $\mathrm{NH}_{3}-\mathrm{N}$ 的 $E P L$ 值远远小于 Qin 等在深圳的研究数据, 原因可能 是合流制排水管道中沉积物的影响. 本研究中 TP 的 $E P L$ 略大于 $\operatorname{Qin}^{[30]}$ 在深圳的研究结果, 这可能是巢湖流 域土壤磷含量高所导致.

表 3 污染物 $E P L$ 值

Tab.3 EPL of pollutants

\begin{tabular}{|c|c|c|c|c|c|}
\hline \multirow{2}{*}{ 日期 } & \multicolumn{5}{|c|}{$E P L /\left(\mathrm{kg} / \mathrm{km}^{2}\right)$} \\
\hline & $\mathrm{TN}$ & $\mathrm{TP}$ & $\mathrm{COD}_{\mathrm{Cr}}$ & SS & $\mathrm{NH}_{3}-\mathrm{N}$ \\
\hline $2015-6-16$ & 59.69 & 13.13 & 863.17 & 5927.70 & 29.55 \\
\hline $2015-6-26$ & 2.98 & 0.45 & 60.35 & 203.91 & 1.24 \\
\hline $2015-7-16$ & 3.32 & 0.32 & 17.37 & 30.84 & 1.32 \\
\hline $2015-7-23$ & 4.21 & 0.53 & 138.40 & 62.71 & 2.66 \\
\hline $2015-8-9$ & 12.74 & 1.66 & 237.31 & 564.50 & 3.50 \\
\hline $2015-8-19$ & 1.94 & 0.15 & 26.15 & 17.29 & 0.81 \\
\hline
\end{tabular}

径流中污染物主要来源于地表污染物积累 ${ }^{[33]}$, 汇水面积越大, 累计污染物越多. 研究区地处合肥市经 济开发区, 工业园区面积占总汇水面积的 $26.41 \%$, 分布着汽车制造、机械加工和包装材料加工等企业, 根据 生产特点, 降雨时可能有油类、脂类、还原性有机物等污染物随径流流人雨水管网; 研究区道路面积占汇水 面积的 $15.92 \%$, 机动车轮胎磨损、汽油润滑油泄漏还有燃料的不完全燃烧会引起 SS、有机物、重金属污 染 ${ }^{[34]}$, 道路两旁的绿化会定期施肥和喷酒农药, 会引起有机物和氮磷营养盐污染; 研究区面积中生活区占 $31.20 \%$, 主要是大学城、居民小区和购物广场, 此区域有较高的人口、车流密度, 餐饮业相对发达, 管理不善 时会出现垃圾无序堆放、餐饮残渣随意倾倒的现象, 所以此区域径流污染物浓度相对较高 ${ }^{[35-36]}$; 占总面积 $26.46 \%$ 的透水区引起的污染最小, 但其中裸地区域会使径流中 SS 增大, 动植物残体会使径流中有机质增 多, 公园绿地施肥会使径流中氮磷营养盐增多. 此外, 大气沉降会在地表积累氮磷 ${ }^{[33-34]}$, 工地会引起径流中 SS 增加, 研究区雨水管道内每天会排人少量生活污水, 虽然量很少, 但流速慢易造成污染物沉积, 影响也不 可忽略 ${ }^{[37]}$. 综合分析表明,径流中污染物主要来源于工业区和生活区地表污染物的积累, 当工业生产和人 类活动有所变化时,径流污染程度可能会有所不同.

表 4 污染物相关性

Tab.4 Correlation among pollutants

\begin{tabular}{ccccc}
\hline 污染物 & $\mathrm{TN}$ & $\mathrm{TP}$ & $\mathrm{COD}_{\mathrm{Cr}}$ & $\mathrm{SS}$ \\
\hline $\mathrm{TP}$ & $0.582^{* *}$ & & & \\
$\mathrm{COD}_{\mathrm{Cr}}$ & $0.467^{* *}$ & $0.567^{* *}$ & & \\
$\mathrm{SS}$ & $0.105^{*}$ & $0.679^{* *}$ & $0.394^{* * *}$ & \\
$\mathrm{NH}_{3}-\mathrm{N}$ & $0.635^{* *}$ & $0.310^{* *}$ & $0.203^{* *}$ & 0.008 \\
\hline
\end{tabular}

** 表示在 0.01 水平 (双侧) 上显著相关, * 表示在 0.05 水平 (双侧) 上显著相关,下同.

\section{2 相关性分析}

雨水径流中各污染指标间的相关性对初期雨 水的治理有重要意义. SS 和 TN、TP 三者分别与 $\mathrm{COD}_{\mathrm{Cr}}$ 之间均呈正相关, 其中 $\mathrm{SS}$ 与 $\mathrm{TP} 、 \mathrm{COD}_{\mathrm{Cr}}$ 的正 相关性更显著 (表 4), 表明 TP 和 $\mathrm{COD}_{\mathrm{Cr}}$ 大部分以颗 粒态存在, 这与王龙涛 ${ }^{[9]}$ 在重庆的研究结论相一 致. 在对初期雨水进行处理时, 以去除 SS 为目的的 物理方法也会对氮磷和有机物有一定的处理效果.

为研究降雨特征对 $E M C$ 和 $E P L$ 值的影响, 分 别将 6 场降雨的 $E M C 、 E P L$ 值与雨强、雨前干期、平 均雨强、最大雨强进行相关性分析, 结果表明雨水径流污染指标中只有 $\mathrm{TN}$ 的 $E M C$ 值与降雨量、平均雨强和 最大雨强之间呈显著负相关, 其余污染指标与降雨特征间不存在显著相关性 (表 5). 随着降雨量的增大, 对 污染源持续的冲刷作用和径流量变大的稀释作用使 TN 浓度变小.

各污染物 $E P L$ 值与 4 种降雨特征间均呈正相关, 与降雨量和最大降雨量均呈显著正相关. 将各污染物 $E P L$ 值与降雨量进行线性拟合得出的公式 (表 6), 可以对任意一场降雨事件中由径流携带流人巢湖的污染 物质量进行估算.6、7、8 月降雨量平均占全年降雨量的 43.55\%, 2015 年研究区 6-8 月期间共有 $10.38 \mathrm{t}$ TN、 
表 $5 E M C 、 E P L$ 值与降雨特征相关性

Tab.5 Correlation between EMC, EPL and rainfall characteristics

\begin{tabular}{cccccc}
\hline \multirow{2}{*}{$E M C$ 值 } & 污染物 & 降雨量 & 雨前干期 & 平均雨强 & 最大雨强 \\
& $\mathrm{TN}$ & $-0.845^{*}$ & -0.670 & $-0.878^{*}$ & $-0.913^{*}$ \\
& $\mathrm{TP}$ & -0.350 & -0.309 & -0.360 & -0.300 \\
& $\mathrm{COD}_{\mathrm{Cr}}$ & -0.491 & -0.220 & -0.312 & -0.481 \\
& $\mathrm{SS}$ & 0.287 & -0.051 & 0.127 & 0.368 \\
\multirow{3}{*}{ 值 } & $\mathrm{NH}_{3}-\mathrm{N}$ & -0.641 & -0.251 & -0.543 & -0.709 \\
& $\mathrm{TN}$ & $0.999^{* *}$ & $0.875^{*}$ & $0.936^{* *}$ & $0.979^{*}$ \\
& $\mathrm{TP}$ & $0.992^{* * *}$ & $0.883^{*}$ & $0.921^{* * *}$ & $0.967^{* * *}$ \\
& $\mathrm{TOD}$ & $0.993^{* *}$ & $0.884^{*}$ & $0.961^{* *}$ & $0.982^{* *}$ \\
& $\mathrm{SS}$ & $0.989^{* *}$ & $0.874^{*}$ & $0.909^{*}$ & $0.962^{* * *}$ \\
& $\mathrm{NH}_{3}-\mathrm{N}$ & $0.988^{* *}$ & $0.902^{*}$ & $0.926^{* *}$ & $0.960^{* *}$ \\
\hline
\end{tabular}

$2.29 \mathrm{t}$ TP、1022.43 t SS、161.70 t $\mathrm{COD}_{\mathrm{Cr}}$ 和 $5.18 \mathrm{t} \mathrm{NH}_{3}-\mathrm{N}$ 随降雨径流排人巢湖.

因污染物主要源于地表污染物积累,所以雨前 干期和降雨量会对污染物浓度产生较大影响,污染 物 $E P L$ 值与降雨特征间均呈正相关, 符合规律, 但各 污染物 $E M C$ 值却与降雨特征间基本无相关性. 当降 雨量小于 $2.5 \mathrm{~mm}$ 且降雨时间较长时,雨水仅使地面 湿润,没有或有少量径流产生,污染物仍留在地表或 在管道内沉积, 6 月 26 日之前的降雨事件中,降雨量 为 $2.8 \mathrm{~mm}$, 仅产生少量径流,所以虽然 6 月 26 日降
表 6 各污染物 $E P L$ 值与降雨量的拟合公式

Tab.6 Fitting formula between EPL of each pollutant and rainfall

\begin{tabular}{ccc}
\hline 污染物 & 公式 & $R^{2}$ \\
\hline $\mathrm{TN}$ & $y=0.7646 x-0.8886$ & 0.9971 \\
$\mathrm{TP}$ & $y=0.1602 x$ & 0.9708 \\
$\mathrm{COD}$ & $y=10.879 x+9.8454$ & 0.9869 \\
$\mathrm{CS}$ & $y=71.488 x$ & 0.9538 \\
$\mathrm{NH}_{3}-\mathrm{N}$ & $y=0.362 x$ & 0.9707 \\
\hline
\end{tabular}

雨事件雨前干期仅为 $1 \mathrm{~d}$,但地表污染物实际经过了 $8 \mathrm{~d}$ 的积累, 所以各污染物浓度相对较高. 8 月 19 日降 雨量最小但部分污染物浓度较大, 6 月 16 日降雨量最大但部分污染物浓度较小, 这是因为雨量小时径流对 污染物的冲刷不完全, 雨量过大时又会产生稀释作用. 7 月 23 日与 7 月 16 日这 2 场降雨事件中, 7 月 23 日 的降雨量与雨前干期大, 径流中各污染物浓度均比 7 月 16 日高, 符合规律. 所以, 虽然从数据上看 $E M C$ 值与 各降雨特征间基本无相关性,但综合分析后可知降雨量和雨前干期是径流污染的主要影响因素.

\section{3 初期冲刷效应分析}

从 $\mathrm{M}(\mathrm{V})$ 曲线图可以看出, 6 场降雨过程中均有污染物表现出初期冲刷效应, 整体来看, 6 月 26 日降雨 的初期冲刷强度相对较强, TN、TP、COD ${ }_{\mathrm{Cr}}$ 和 $\mathrm{SS}$ 的 FF50 均超过 $60, \mathrm{COD}_{\mathrm{Cr}}$ 初期冲刷效应最强烈, 达 $92.06, \mathrm{TN}$ 和 $\mathrm{NH}_{3}-\mathrm{N}$ 在 6 月 16 日的降雨过程中未出现初期冲刷, 两者表现出了 “后期冲刷” (图 4); 单次降雨过程中, 不同污染物表现出不同的冲刷强度, 各污染物 FF50 平均值表现为 $\mathrm{SS}>\mathrm{COD}_{\mathrm{Cr}}>\mathrm{TP}>\mathrm{TN}>\mathrm{NH}_{3}-\mathrm{N}$, 可以看出 $\mathrm{SS}$ 和 $\mathrm{COD}_{\mathrm{Cr}}$ 的初期冲刷效应相对显著 (图 5), 这与 $\mathrm{Li}$ 等 ${ }^{[38]}$ 在武汉的研究结果相类似; 5 种污染物中只有 $\mathrm{TP}$ 在 6 场降雨过程中均出现初期冲刷现象, 其 FF50 平均值达 $61.90 ; \mathrm{NH}_{3}-\mathrm{N}$ 的初期冲刷强度最弱, 只出现 3 次初 期冲刷现象,其 FF50 平均值小于 50 .

雨型会对初期冲刷现象产生一定影响, 根据降雨过程中雨强的分布变化, 6 次降雨事件的雨型可分为: 6 月 26 日和 7 月 23 日为前期单峰型, 雨强峰出现在降雨过程前期; 7 月 16 日和 8 月 19 日为中期单峰型, 雨强 峰出现在降雨过程中期; 6 月 6 日和 8 月 9 日为多峰型, 降雨过程中出现多个雨强峰. 比较不同雨型各污染 物的 FF50 平均值, 发现同一污染物在不同降雨雨型中 FF50 平均值差别较大, 说明雨型对初期冲刷现象有 较大影响. 前期单峰型降雨各污染物 FF50 平均值均最大且均超过 50, 多峰型降雨除 TP 外, 其他污染物 FF50 平均值均最小, 可见前期单峰型降雨最容易出现初期冲刷现象 (表 7).

与小汇水面源头冲刷 ${ }^{[39]}$ 相比, 本次研究中的初期冲刷强度相对较弱. 与其他地区的管渠冲刷相比, 也 得出了几点不一致的结论, 例如: Taebi 等 ${ }^{[40]}$ 对伊朗某城市进行径流污染研究后, 认为降雨强度及降雨量越 


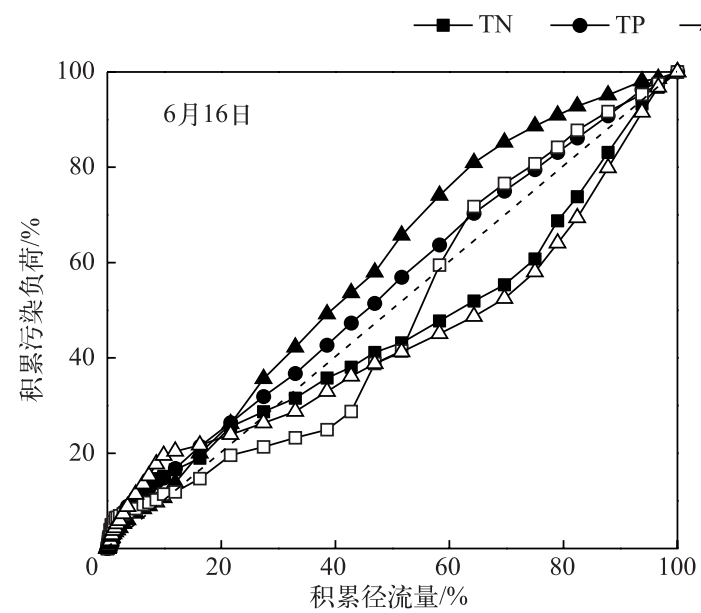

$$
\text { SS } \square-\mathrm{COD}_{\mathrm{Cr}} \longrightarrow-\mathrm{NH}_{3}-\mathrm{N}
$$
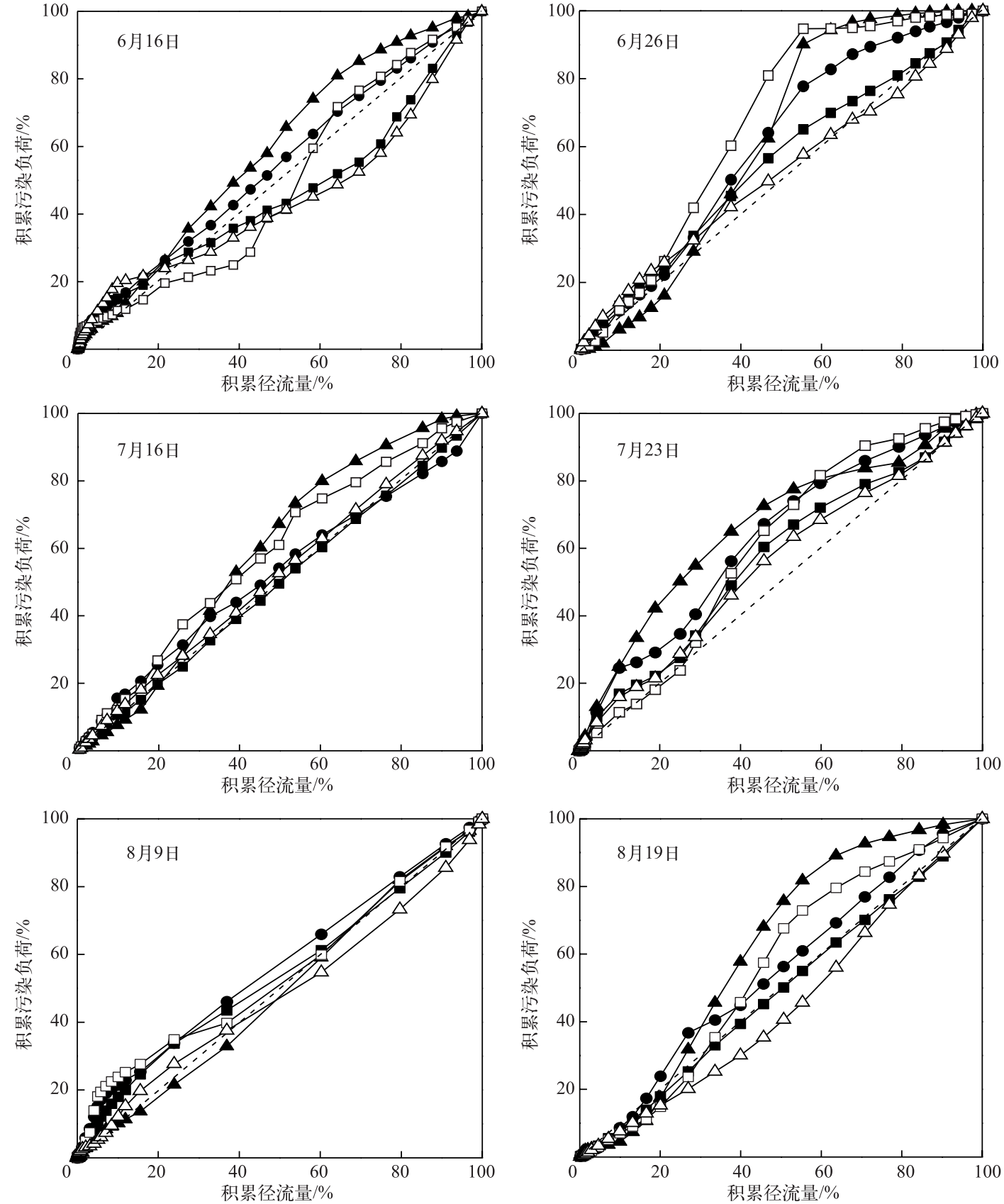

图 46 次降雨的 $\mathrm{M}(\mathrm{V})$ 曲线

Fig.4 The $M(V)$ curve of six rainfall events

大, 初期冲刷效应越明显; $\mathrm{Li}$ 等 ${ }^{[38]}$ 在武汉的研究显示雨前干期越长, 初期冲刷越明显. 通过分析本次研究数 据发现, 初期冲刷强度与各降雨特征间无相关性. 造成研究结果有差异的原因是多方面的, 研究区汇水面积 越大, 径流的产生和输送过程越为复杂. 本研究区汇水面积与以往研究相比较大, 降雨类型、土地利用类型、 管道特征和管道内沉积物等因素对径流的流量水质、初期冲刷效应强度的影响均会因汇水面积的增大而变 


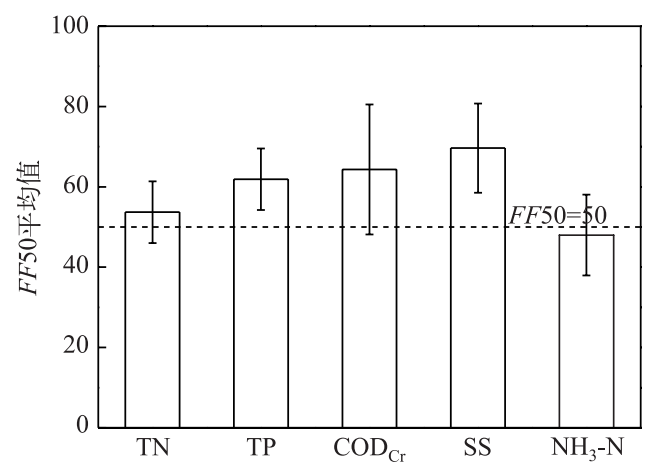

图 5 污染物 FF50 平均值

Fig.5 Average FF50 of pollutants

大. Sztruhár 等 ${ }^{[41]}$ 指出径流在管道内的汇流时间会对是否发生初期冲刷有显著影响. 王俊松等 ${ }^{[42]}$ 对昆明 3 个集水区的降雨径流分别进行监测研究,得到降雨历时和雨前干期对初期冲刷无明显影响的结论. 谭琼 等 ${ }^{[43]}$ 对上海合流制排水系统的研究也表明,各水质指标初期冲刷效应随汇水面积的增大而减小.

表 7 不同雨型的 $F F 50$ 平均值

Tab.7 Average FF50 of different rainfall patterns

\begin{tabular}{cccccc}
\hline \multirow{2}{*}{ 雨型 } & \multicolumn{5}{c}{$F F 50$} \\
\cline { 2 - 6 } & $\mathrm{TN}$ & $\mathrm{TP}$ & $\mathrm{COD}_{\mathrm{Cr}}$ & $\mathrm{SS}$ & $\mathrm{NH}_{3}-\mathrm{N}$ \\
\hline 前期单峰型 & 62.96 & 72.56 & 80.69 & 79.46 & 57.55 \\
中期单峰型 & 50.10 & 56.24 & 66.91 & 73.07 & 47.22 \\
多峰型 & 47.98 & 56.90 & 45.32 & 56.38 & 39.23 \\
\hline
\end{tabular}

\section{4 初期雨水工程调蓄净化建议}

由于研究区在降雨过程中产生的径流量大且污染显著, 需要采取工程措施对初期雨水进行调蓄净化. 通过以上研究可知, 研究区降雨虽然存在初期冲刷效应, 但冲刷强度较弱, 需对大量径流进行截流处理, 结 合 8 月 19 日降雨数据可知, 当降雨强度为 $1.36 \mathrm{~mm} / \mathrm{h}$ 时地面会产生径流进行汇集. 潘国庆等 ${ }^{[4]}$ 通过对合肥 30 年的降雨量日值资料进行统计分析, 得到合肥的设计降雨量为 $31.4 \mathrm{~mm}$, 即 $24 \mathrm{~h}$ 内, 控制前 $31.4 \mathrm{~mm}$ 的降 雨量可以处理 $85.9 \%$ 的年径流污染. 但设计降雨量只是从降雨事件控制率出发, 没有考虑具体的水质状况, 通常后期径流污染物浓度会降低. 结合本研究中 6 月 16 日降雨数据进行计算, 得出研究区降雨 $31.4 \mathrm{~mm}$ 时 产生的径流量为 $224319.14 \mathrm{~m}^{3}$.

本研究 6 场降雨事件中有 5 场降雨量未超过 $21 \mathrm{~mm}$, 通过研究合肥市 $2011-2015$ 年近 5 年降雨数据可 知:5-9 月日降雨量小于 $21 \mathrm{~mm}$ 的天数占总降雨天数的 $78.51 \%$. 所以可将日降雨量小于 $21 \mathrm{~mm}$ 的降雨径流 全部截流, 超过 $21 \mathrm{~mm}$ 的降雨截取最大径流量取 $224319.14 \mathrm{~m}^{3}$. 考虑到截流的可操作性, 可从时间上进行截 流. 8 月 9 日径流从产生汇集到完全流出用时 $440 \mathrm{~min}$, 所以从有径流流出开始计时,截取前 $440 \mathrm{~min}$ 内流出 的径流, 调蓄池体积可参考 $224319.14 \mathrm{~m}^{3}$ 进行设计, 当截取的径流量在前 $440 \mathrm{~min}$ 便达到 $224319.14 \mathrm{~m}^{3}$ 时, 可 在达到时刻停止截流.

调蓄方案可设计为: 当降雨强度达 $1.36 \mathrm{~mm} / \mathrm{h}$ 即有径流汇集流出时开始截流, 截流时间取 $440 \mathrm{~min}$, 截取 的最大径流量取 $224319.14 \mathrm{~m}^{3}$. 用此方案单次降雨最多可削减 $0.49 \mathrm{t} \mathrm{TN} 、 0.13 \mathrm{t} \mathrm{TP} 、 67.99 \mathrm{t} \mathrm{SS} 、 5.07 \mathrm{t} \mathrm{COD}_{\mathrm{Cr}}$ 和 $0.22 \mathrm{t} \mathrm{NH}_{3}-\mathrm{N}$ 排人巢湖. 若以此方案对 6 月 16 日降雨进行截流, 截流后流人巢湖的径流中 $\mathrm{TN}$ 浓度为 $1.83 \mathrm{mg} / \mathrm{L} 、 \mathrm{TP}$ 浓度为 $0.37 \mathrm{mg} / \mathrm{L} 、 \mathrm{COD}_{\mathrm{Gr}}$ 浓度为 $30.39 \mathrm{mg} / \mathrm{L} 、 \mathrm{NH}_{3}-\mathrm{N}$ 浓度为 $0.95 \mathrm{mg} / \mathrm{L}, \mathrm{TP}$ 和 $\mathrm{COD}_{\mathrm{Cr}}$ 与合肥地 表水体水质控制目标已非常接近.

对初期雨水的处理不能仅靠雨水径流的截流调蓄净化, 针对汇水面的源头处理和对管道沉积物的清 
理, 同样可以对初期雨水的治理起到重要作用. 调蓄方案中截流时间仅靠一场降雨确定, 存在较大误差, 需 要多次数据进行验证改进.

\section{3 结论}

1) 研究区雨水径流中各污染物浓度前期波动较大且浓度较高, 随着降雨的进行浓度迅速降低, 变化趋 于平稳; 降雨径流中 $\mathrm{SS} 、 \mathrm{COD}_{\mathrm{Cr}}$ 和 $\mathrm{TP}$ 的 $E M C$ 值相对较高; $\mathrm{SS}$ 的 $E M C$ 值波动最为显著.

2) 雨水径流中 TN、TP、COD 、 $、$ S 间均呈正相关, 对初期雨水中携带的悬浮颗粒物进行强制沉降有助于 削减各种污染负荷; TN 的 $E M C$ 值受降雨量的影响较大, 两者呈负相关; 各污染物 $E P L$ 值与各降雨特征间均 呈正相关性, 经估算 2015 年研究区在 6-8 月期间共有 10.38 t TN、2.29 t TP、1022.43 t SS、161.70 t COD Cr $_{\text {和 }}$ $5.18 \mathrm{t} \mathrm{NH}_{3}-\mathrm{N}$ 随降雨径流排人巢湖; 降雨量和雨前干期是径流污染的主要影响因素.

3 ) 以 FF50>50 为初期冲刷效应判别依据, 5 种污染物均有初期冲刷效应出现, 冲刷强度表现为 SS> $\mathrm{COD}_{\mathrm{Cr}}>\mathrm{TP}>\mathrm{TN}>\mathrm{NH}_{3}-\mathrm{N}$; 各水质指标的初期冲刷强度与降雨特征之间无相关性; 雨型对初期冲刷现象影响 较大.

4) 当降雨强度达 $1.36 \mathrm{~mm} / \mathrm{h}$ 即有径流汇集流出时开始截流,截取时间取 $440 \mathrm{~min}$,截取的最大径流量取 $224319.14 \mathrm{~m}^{3}$, 单次降雨最多可削减 $0.49 \mathrm{t}$ TN、0.13 t TP、67.99 t SS、5.07 t $\mathrm{COD}_{\mathrm{Cr}}$ 和 0.22 t $\mathrm{NH}_{3}-\mathrm{N}$ 排人巢湖.

\section{4 参考文献}

[ 1 ] Zhang Min, Kong Fanxiang. The process, spatial and temporal distributions and mitigation strategies of the eutrophication of Lake Chaohu( 1984-2013). J Lake Sci, 2015, 27(5) : 791-798. DOI: 10.18307/2015.0505. [张民, 孔繁翔. 巢湖 富营养化的历程，空间分布与治理策略(1984-2013 年). 湖泊科学, 2015, 27 (5): 791-798. ]

[ 2 ] Yu Hui. Integrated control of pollution sources in Lake Biwa Basin, Japan and its successful experience in lake eutrophication management. Research of Environmental Sciences, 2014, 27(11): 1243-1250. [ 余辉. 日本琵琶湖污染源系统控制 及其对我国湖泊治理的启示. 环境科学研究, 2014, 27(11) : 1243-1250.]

[ 3 ] Che Wu, Zhao Yang, Li Junqi et al. Explanation of sponge city development technical guide: Basic concepts and comprehensive goals. China Water \& Wastewater, 2015, 31(8): 1-5. [车伍, 赵杨, 李俊奇等. 海绵城市建设指南解读之基 本概念与综合目标. 中国给水排水, 2015, 31(8): 1-5.]

[ 4 ] Lee JH, Bang KW. Characterization of urban stormwater runoff. Water Research, 2000, 34( 6) : 1773-1780.

[ 5 ] Pongmala K, Autixier L, Madoux-Humery AS et al. Modelling total suspended solids, E. coli and carbamazepine, a tracer of wastewater contamination from combined sewer overflows. Journal of Hydrology, 2015, 531(11) : 830-839.

[ 6 ] Shen Z, Liu J, Aini G et al. A comparative study of the grain-size distribution of surface dust and stormwater runoff quality on typical urban roads and roofs in Beijing, China. Environmental Science and Pollution Research, 2016, 23(3) : 1-12.

[ 7 ] Pan Jun, Chen Yuqi, Dong Jian et al. Heavy metal distribution characteristics in the rainwater runoff of Shenyang zone. Journal of Shenyang Jianzhu University: Natural Science, 2015, 31(4): 730-736. [潘俊, 陈昱奇, 董健等. 沈阳城区 雨水径流中重金属的分布特征. 沈阳建筑大学学报: 自然科学版, 2015, 31(4): 730-736.]

[ 8 ] Verdaguer M, Clara N, Gutiérrez O et al. Application of Ant-Colony-Optimization algorithm for improved management of first flush effects in urban wastewater systems. Science of the Total Environment, 2014, 485(12) : 143-152.

[ 9 ] Wang Longtao, Duan Bingzheng, Zhao Jianwei et al. Pollution characteristics of surface runoff of typical town in Chongqing city. Environmental Science, 2015, 36(8): 2809-2816. [王龙涛, 段丙政, 赵建伟等. 重庆市典型城镇区地表径流污 染特征. 环境科学, $2015, \mathbf{3 6}(8)$ : 2809-2816.]

[10] Sun S, Barraud S, Castebrunet $\mathrm{H}$ et al. Long-term stormwater quantity and quality analysis using continuous measurements in a French urban catchment. Water Research, 2015, 85(15) : 432-442.

[11] Brezonik PL, Stadelmann TH. Analysis and predictive models of stormwater runoff volumes, loads, and pollutant concentrations from watersheds in the Twin Cities metropolitan area, Minnesota, USA. Water Research, 2002, 36 ( 7 ): 1743-1757.

[12] Li Chunlin, Liu Miao, Hu Yuanman et al. Analysis of first flush in rainfall runoff in Shenyang urban city. Acta Ecologica Sinica, 2013, 33(18): 5952-5961. [李春林, 刘氷, 胡远满等. 沈阳市降雨径流初期冲刷效应. 生态学报, 2013, 
33(18): 5952-5961.]

[13] Ma ZB, Ni HG, Zeng $\mathrm{H}$ et al. Function formula for first flush analysis in mixed watersheds: A comparison of power and polynomial methods. Journal of Hydrology, 2011, 402(3) : 333-339.

[14] Che Wu. Zhang Wei, Li Junqi. Analysis of urban initial rainwater and first flush. China Water \& Wastewater, 2011, 27 (14) : 9-14. [ 车伍, 张伟, 李俊奇. 城市初期雨水和初期冲刷问题剖析. 中国给水排水, 2011, 27(14) : 9-14.]

[15] Li Chunlin, Hu Yuanman, Liu Miao et al. Urbannon-point source pollution: Research progress. Chinese Journal of Ecolo$g y, 2013,32(2):$ 492-500. [李春林, 胡远满, 刘沝等. 城市非点源污染研究进展. 生态学杂志, 2013, 32(2): 492-500.]

[16] Geiger W. Flushing effects in combined sewer systems. Proceedings of the 4th International Conference Urban Drainage. Lausanne, Switzerland, 1987: 46.

[17] Bertrand-Krajewski JL, Chebbo G, Saget A. Distribution of pollutant mass vs volume in stormwater discharges and the first flush phenomenon. Water Research, 1998, 32(8) : 2341-2356.

[18] Saget A, Chebbo G, Bertrand-Krajewski JL. The first flush in sewer systems. Water Science and Technology, 1996, 33 (9) : 101-108.

[19] Gupta K, Saul AJ. Specific relationships for the first flush load in combined sewer flows. Water Research, 1996, 30(5): 1244-1252.

[20] Lang M, Li P, Yan X. Runoff concentration and load of nitrogen and phosphorus from a residential area in an intensive agricultural watershed. Science of the Total Environment, 2013, 458(3) : 238-245.

[21] Li Junqi, Mao Kun, Xiang Lulu. Research on runoff pollution load and first flush effect of Jingcheng highway. China Water \&Wastewater, 2010, 26(18): 59-63. [李俊奇, 毛坤, 向璐璐. 京承高速公路径流污染负荷及初期冲刷效应研究. 中国给水排水, $2010,26(18): 59-63$. ]

[22] Revitt DM, Lundy L, Coulon F et al. The sources, impact and management of car park runoff pollution: A review. Journal of Environmental Management, 2014, 146(15) : 552-567.

[23] Park I, Kim H, Chae SK et al. Probability mass first flush evaluation for combined sewer discharges. Journal of Environmental Sciences, 2010, 22(6): 915-922.

[24] Xu Wei. Investigation and analysis on water quality and quantity of separate storm system in Chaohu city [ Dissertation]. Wuhan: Wuhan University of Technology, 2013. [徐伟. 巢湖市分流制雨水系统水质水量调查与分析 [ 学位论文]. 武汉: 武汉理工大学, 2013.]

[25] Schmitt N, Wanko A, Laurent J et al. Constructed wetlands treating stormwater from separate sewer networks in a residential Strasbourg urban catchment area: Micropollutant removal and fate. Journal of Environmental Chemical Engineering, $2015, \mathbf{3}(4)$ : 2816-2824.

[26] Tang Lei, Che Wu, Zhao Yang et al. Research on first flush of combine sewer overflow and control. Water \& Wastewater Engineering, 2014, 40(5): 24-30. [唐否, 车伍, 赵杨等. 合流制溢流初期冲刷及其控制策略研究. 给水排水, $2014, \mathbf{4 0}(5): 24-30$.

[27] Wu Lei. Application of Chao Lake water to ecological water supplement of urban landscape river. China Water \& Wastewater, 2013, 29(6) : 69-72. [ 吴蕾. 巢湖水用于城市景观河道生态补水工程. 中国给水排水, 2013, 29(6): 69-72.]

[28] Editorial Board of Water and Wastewater Monitoring and Analysis Methods, Ministry of Environmental Protection of the People's Republic of China ed. Water and wastewater monitoring and analysis methods: 4th edition. Beijing: China Environmental Science Press, 2002. [ 国家环境保护总局《水和废水监测分析方法》编委会. 水和废水监测分析方法: 第 4 版. 北京: 中国环境科学出版社, 2002.]

[29] Sansalone JJ, Buchberger SG. Partitioning and first flush of metals in urban roadway storm water. Journal of Environmental Engineering, 1997, 123(2): 134-143.

[ 30] Qin HP, Khu ST, Yu XY. Spatial variations of storm runoff pollution and their correlation with land-use in a rapidly urbanizing catchment in China. Science of the Total Environment, 2010, 408(20) : 4613-4623.

[31] Xie Jifeng, Hu Zhixin, Xu Ting et al. Water quality characteristics of rainfall runoff in Hefei City. China Environmental Science, 2012, 32(6) : 1018-1025. [谢继锋, 胡志新, 徐挺等. 合肥市不同下垫面降雨径流水质特征分析. 中国环 境科学, 2012, 32(6): 1018-1025.] 
[32] Zhou Huiping, Gao Chao, Sun Bo et al. Spatial variation characteristics and its driving factors of total phosphorus in topsoil of Chaohu Lake watershed. Journal of Agro-Environment Science, 2008, 26(6): 2112-2117. [ 周慧平, 高超, 孙波等. 巢 湖流域土壤全磷含量的空间变异特征和影响因素. 农业环境科学学报, 2008, 26(6) : 2112-2117.]

[33] Han Bing, Wang Xiaoke, Ouyang Zhiyun. Analysis on characteristics of urban non-point source pollution. Water Resources Protection, 2005, 21(2) : 1-4. [ 韩冰, 王效科, 欧阳志云. 城市面源污染特征的分析. 水资源保护, 2005, 21(2): 1-4. ]

[34] Zhang Qianqian, Wang Xiaoke, Hao Liling et al. Characterization and source apportionment of pollutants in urban roadway runoff in Chongqing. Environmental Science, 2012, 33(1): 76-82. [张千千, 王效科, 郝丽岭等. 重庆市路面降雨径 流特征及污染源解析. 环境科学, 2012, 33(1): 76-82.]

[35 ] Ma Ying, Ma Yongwen, Wan Jinquan et al. Characterization of rainfall runoff pollution transportation in different underlying surface of Dongguan City. China Environmental Science, 2011, 31(12) : 1983-1990. [马英, 马鱼文, 万金泉等. 东 莞不同下垫面降雨径流污染输移规律研究. 中国环境科学, 2011, 31(12) : 1983-1990.]

[36] Huang Jinliang, Du Pengfei, Ou Zhidan et al. Characterization of urban surface runoff in two urban catchments in Macau. Environmental Science, 2006, 27(9): 1753-1759. [黄金良, 杜鹏飞, 欧志丹等. 澳门城市小流域地表径流污染特征 分析. 环境科学, 2006, 27(9): 1753-1759.]

[37] Pan Guoqing, Che Wu, Li Haiyan et al. Effect of storm sewer sediment on first flush. Acta Scientiae Circumstantiae, 2009, 29(4) : 771-776. [潘国庆, 车伍, 李海燕等. 雨水管道沉积物对径流初期冲刷的影响. 环境科学学报, 2009,29 (4): $771-776$.

[38 ] Li LQ, Yin CQ, He QC et al. First flush of storm runoff pollution from an urban catchment in China. Journal of Environmental Sciences, 2007, 19(3): 295-299.

[39] Ren Yufen, Wang Xiaoke, Ouyang Zhiyun et al. Analysis of first flush effect of typical underlying surface runoff in Beijing urban city. Environmental Science, 2013, 34(1):373-378. [任玉芬, 王效科, 欧阳志云等. 北京城市典型下垫面降 雨径流污染初始冲刷效应分析. 环境科学, 2013, 34(1): 373-378.]

[40] Taebi A, Droste RL. First flush pollution load of urban stormwater runoff. Journal of Environmental Engineering and Science, 2004, 3(4) : 301-309.

[41] Sztruhár D, Sokáč M, Holienčin A et al. Comprehensive assessment of combined sewer overflows in Slovakia. Urban Water, 2002, 4(3): 237-243.

[42] Wang Junsong, Zhao Lei, Zhang Xiaoxu. First flush effect analysis of urban storm runoff in combine sewer system. Environmental Pollution \& Control, 2015, 37(2): 12-20. [王俊松, 赵否, 张晓旭. 合流制排水系统降雨径流初期冲刷效应. 环境污染与防治, 2015, 37(2): 12-20.]

[43] Tan Qiong, Li Tian, Gao Qiuxia. Analysis on the first flush effect of stormwater discharge from Shanghai drainage system. China Water and Wastewater, 2005, 21(11) : 26-30. [谭琼, 李田, 高秋霞. 上海市排水系统雨天出流的初期效应分 析. 中国给水排水, 2005, 21(11): 26-30.]

[44] Pan Guoqing, Che Wu, Li Junqi et al. Urban runoff pollution control quantity and its design rainfall in China. China Water and Wastewater, 2008, 24(22): 25-29. [潘国庆, 车伍, 李俊奇等. 中国城市径流污染控制量及其设计降雨量. 中 国给水排水, 2008, 24(22) : 25-29.] 